\title{
Darkness sharpens hearing in adult mice
}

Rapid brain-cell changes in animals kept in the dark give them better discrimination of sounds.

Dinsa Sachan

05 February 2014

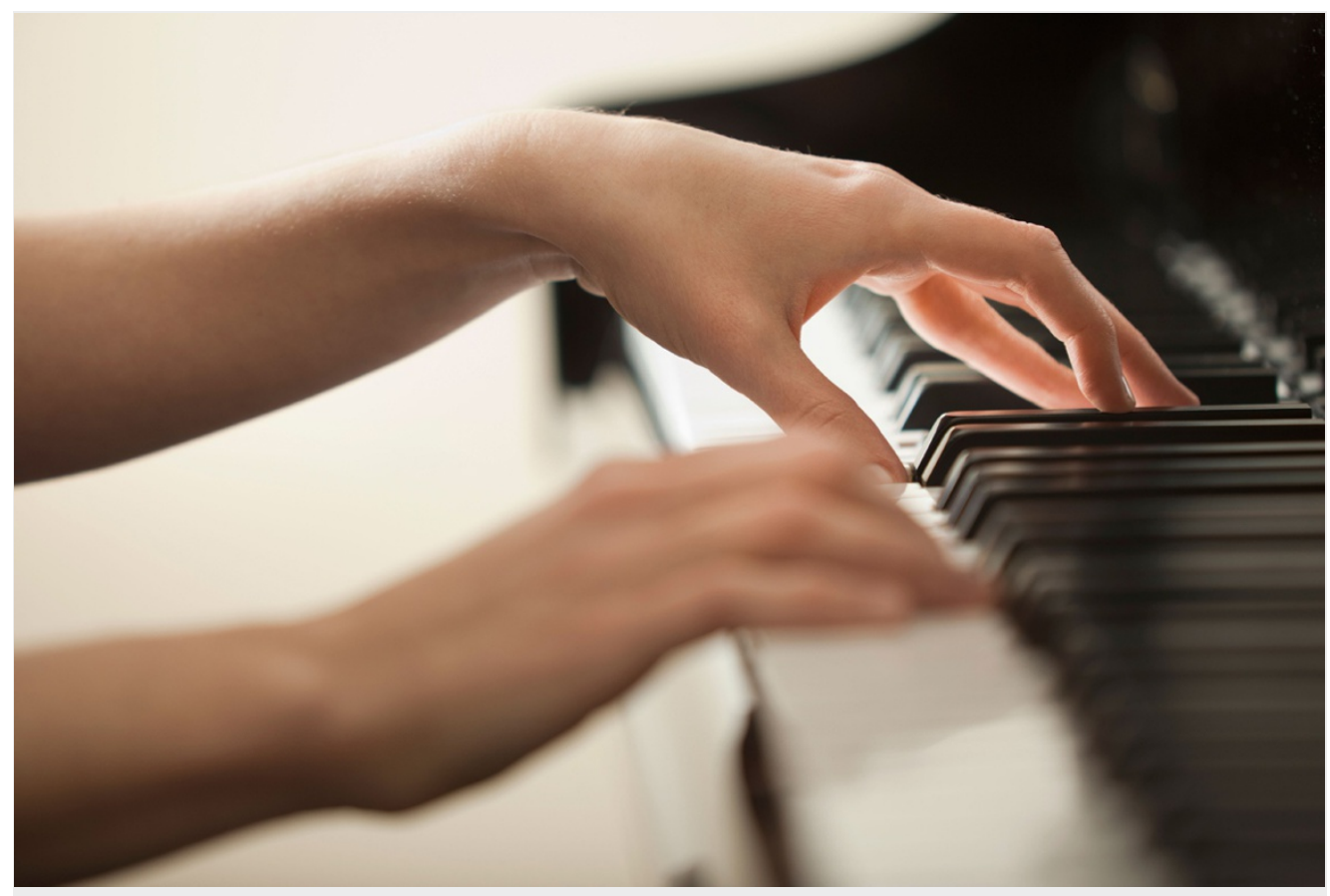

Tetra Images / Alamy

The loss of sight — whether temporary or permanent — could bring improved musical aptitude.

Could being visually impaired have had a role in the musical genius of Stevie Wonder and Ray Charles? A study provides some clues by showing that adult mice kept in the dark quickly develop sharper hearing and become better at distinguishing pitch and frequency. The improvements were correlated with adaptations in the brain — such as strengthening of connections between neurons — that normally happen only early in life.

For their study, published today in Neuron ${ }^{1}$, Hey-Kyoung Lee, a neuroscientist at Johns Hopkins University in Baltimore, Maryland, and her collaborators selected two sets of healthy adult mice. They kept the first group in a darkened environment for a week, while the other was exposed to natural light. The team used electrodes to measure activity in neurons in the animals' primary auditory cortex - the part of the brain that processes what a sound is, how loud it is and where it comes from.

The researchers played sounds of different frequencies and intensities to the mice, and watched how their brain cells reacted. The results "showed that neurons in visually deprived animals can 'hear' much softer sounds" than in control animals, says Lee. "They also have much finer discrimination ability as far as identifying pitch goes."

Previous studies ${ }^{2}$ have found that changes in the auditory cortex take a long time, and that people who become blind early in life adapt better than those who lose their sight later. The team's findings, however, show that some modifications can occur rapidly in the adult brain, she says. "Moreover," she adds, "the changes in the auditory cortex were achieved by changes in the strength of synaptic connections. These were believed to be unchangeable in adults."

\section{Sensory compensation}

The results also provide some basis for the claim that visual impairment can aid musicians ${ }^{3}$. "There's some evidence that if you don't have vision, you can locate sound better," says Lee. But, she adds, studies on humans either use brain imaging — which does not get to the fine detail — or look at behaviour. "We've looked at the level of neurons, and provided a cellular basis for how these functional changes happen at the behavioural level." 
The sensory changes in mice were temporary, but the findings could show researchers how to improve hearing in deaf people. "A lot of people are trying to recover their hearing through cochlear implants. They work very well in younger children, who recover perfectly," Lee explains. "But adults who are completely deaf have a difficult time recovering their hearing even with these devices." Brief periods of visual deprivation could help people learn to process sound after receiving implants, she says.

Study co-author Patrick Kanold, a biologist at the University of Maryland in College Park, notes that visual deprivation might not have the same effect on humans as on mice. "Future work will identify if such deprivations are effective in humans. For example, while one week of deprivation showed effects in mice, for humans longer deprivations might be needed," he says.

The result "is somewhat surprising", says Pawan Sinha, a neuroscientist studying vision at the Massachusetts Institute of Technology in Cambridge. He adds that researchers have previously reported modest improvements in sound localization abilities in blind humans ${ }^{4}$, but basic auditory thresholds seemed largely unaffected. "Evidence of sensory enhancement in blind humans is rather tentative."

Nature | doi:10.1038/nature.2014.14677

\section{References}

1. Petrus, E. et al. Neuron 81, 664-673 (2014).

2. Gougoux, F. et al. Nature 430, 309 (2004).

3. Röder, B. et al. Nature 400, 162-165 (1999).

4. Ashmead, D. H. et al. Perception 27, 105-122, (1998). 